\title{
Percepções da comunidade universitária sobre o Bosque do Planetário - Campus Universitário da UFSC*
}

\author{
Ariane Kuhnen ${ }^{l}$ \\ Universidade Federal de Santa Catarina
}

Esse estudo buscou conhecer a percepção da comunidade universitária sobre uma importante área verde da UFSC, o Bosque do Planetário. Aplicou-se um questionário com 1292 sujeitos, entre professores, estudantes e servidores. Foram feitas análises do tipo descritivo e relacional. Como resultados tem-se que, a oportunidade de contato com a natureza (563 dos entrevistados), tranquilidade (404), silêncio (384), área de lazer (308) e, a privacidade (127) são os aspectos positivos apontados. Quase a totalidade $82,4 \%$ já ouviu falar do Bosque. Pouco mais da metade, $54,7 \%$, já estiveram no local e, pouco menos da metade $45,3 \%$ não. $35 \%$ justificam não ir ao Bosque por não saber da sua existência e, 17,6\% nunca ouviu falar, mas $68,6 \%$ gostariam de conhecê-lo. De fato, o Bosque tem sido evitado por problemas relacionados à segurança. Conclusivamente observa-se que uma importante área verde não vem recebendo atenção. Os futuros gestores poderiam qualificar o local como um parque, valorizando-o para atividades acadêmicas e desenvolvimento comunitário local e da cidade, prevenindo o uso inadequado da área.

Palavras-chave: Espaços abertos - Psicologia ambiental - Ambientes restauradores - Campus Universitário - UFSC
This study aim to know the perception of an important green area of UFSC, the Bosque do Planetário. 1292 subjects participated between teachers, students and servers. We applied a questionnaire by interview. Analyzes were performed descriptive and relational. As a result we have that, the opportunity to connect with nature (563 of respondents), tranquility (404), silence (384), leisure area (308) and privacy (127) are the positive aspects mentioned. Almost the entire sample $82.4 \%$ have heard of the Bosque. Just over half, $54.7 \%$, were already on site, just under half $45.3 \%$ did not. $35 \%$ justifies not going to groove for not knowing of its existence, and $17.6 \%$ never heard of, but $68.6 \%$ would like to meet you. In fact, the grove has been avoided by security issues. Conclusively shows that an important green area has received no attention. Future managers could qualify the site as a park, valuing it for academic activities and local community development and the city, preventing the inappropriate use of the area.

Keywords: Open spaces - Environmental psychology - Restorative environments - Campus - UFSC

\footnotetext{
* Perceptions of the university community about the Bosque do Planetário - UFSC campus

${ }^{1}$ Agradeço a colaboração dos estudantes da disciplina Psicologia Ambiental que participaram da coleta de dados, a aluna de psicologia Ingrid Kuhnen Coelho e a estagiária docência de pós-graduação Gislei M. Polli pelo auxílio na organização do artigo e na coordenação da pesquisa de campo e tratamento dos dados. Endereço para correspondências: Universidade Federal de Santa Catarina, Departamento de Psicologia, Campus Universitário, Florianópolis, SC, 88040-970 (ariane@cfh.ufsc.br).
} 
Introdução

Diretrizes para desenvolver hipóteses sobre o papel dos diferentes componentes do ambiente na saúde humana vêm sendo divulgadas pelos canais de comunicação em geral assim como pela comunidade científica. Mais especificamente, a área de estudos pessoa-ambiente vem tratando a relação entre os seres humanos e o ambiente físico, seja o natural ou o construído, como bidirecional, ou melhor dizendo, se aceita a premissa de que ocorre uma mútua interferência entre a pessoa e o ambiente. Muitos são os aportes teóricos de apoio a essa dimensão. A colaboração entre domínios disciplinares, aparentemente distantes, tem se mostrado imprescindível à compreensão das relações pessoa-ambiente em toda a sua complexidade. Destaca-se a importância dos aportes teórico-metodológicos que a Psicologia Ambiental vem oferecendo ao conjunto desses trabalhos. Resultante de um momento importante na sociedade, o paradigma da interdisciplinaridade figura desde o início de sua formação.

A Psicologia Ambiental é uma das áreas dentre um grande grupo de pesquisadores, localizados em várias partes do mundo, que vêm se dedicando a pensar as formas de uso do ambiente físico. Desde a sua concepção tem se comprometido com o desenvolvimento de uma disciplina orientada para problemas, priorizando pesquisas com o objetivo de resolver complexos problemas ambientais, na busca do bem-estar individual dentro de uma sociedade maior. Subdisciplina da ciência psicológica, vê-se empenhada em investigar e compreender os processos psicossociais decorrentes das interrelações entre as pessoas e os seus entornos sócio-físicos.

Amplamente falando, desde as recomendações da II Conferência das Nações Unidas sobre o Meio Ambiente e Desenvolvimento, a preocupação com as gerações futuras, a garantia de qualidade de vida, a participação das pessoas na tomada de decisões e na busca de soluções para os problemas da relação sociedade-meio ambiente tem avançado também no campo da ciência. Em termos de planejamento dos ambientes tem sido demonstrado o impacto da inclusão dos usuários nos processos de decisão por promover o apego ao lugar, aumentar o senso de responsabilidade, o cuidado e as práticas ambientais sustentáveis, o engajamento cívico, a instauração de valores de cidadania e a democracia.

Vínculos emocionais com lugares têm sido relacionados à mobilização para o planejamento ambiental comunitário, engajamento e controle social (MANZO \& PERKINS, 2006; WAKEFIELD et al., 2001;). A afetividade que as pessoas estabelecem com lugares decorre da percepção do papel que os laços apresentam na definição e na qualificação da identidade pessoal, instauram o sentido de pertencimento a um lugar e promovem a apropriação e o cuidado ambientais 
Tomando essas orientações a Psicologia Ambiental vem travando um diálogo teórico-metodológico com outras áreas, como a educação e o desenvolvimento psicológico, discutindo a relação entre a pessoa em desenvolvimento e o ambiente físico, entre as concepções arquitetônicas e o projeto educativo. Nesse sentido, estudos mostram que a convivência com áreas verdes aumenta a concentração do aluno e contribui diretamente para o seu amadurecimento emocional e para suas relações sociais (ARBOGAST et al., 2009; TAYLOR, 2001; TAYLOR et al., 1998). Ambientes restauradores na escola, que promovam conforto, sensações agradáveis e identificação, também contribuem para a promoção de vínculos afetivos com o lugar e, por conseguinte, o cuidado ambiental (SHALLCROSS et al., 2007; GEARIN \& KAHLE, 2006; TRAVLOU et al., 2008).

Os vínculos podem também servir como um mecanismo de controle ambiental, em que se manifesta o poder de intervenção e influência dos usuários sobre o meio. Através desse mecanismo, as pessoas organizam o espaço ao seu redor para atender às suas necessidades. Os efeitos de visualização das características da paisagem natural com níveis elevados de vegetação estão relacionados com o rendimento escolar, a realização pessoal e o funcionamento mental, por exemplo, em um estudo com estudantes universitários com acesso a pontos de vista natural através das janelas do dormitório demonstrou-se que esses tiveram melhor desempenho em testes de atenção dirigida do que os que tinham visão parcial ou total de ambiente construído (TENNESSEN \& CIMPRICH, 1995). Sabe-se também que o contato com o ambiente natural promove populações mais saudáveis (KAPLAN, 1995, 2001; BERG et al., 2007; VELARDE et al., 2007). A literatura sugere ainda que existem cinco pontos principais em que a exposição à natureza é benéfica para a saúde humana como o reforço de competências pessoais e sociais de comunicação; o aumento da saúde física e bem-estar; da saúde mental e espiritual; da percepção sensorial e estética e; habilidade para firmar o controle pessoal e aumentar a sensibilidade ao seu próprio bem-estar (MORRIS, 2003).

Em 1982 Zube e colaboradores publicaram Landscape perception: research, application, and theory. Foi o primeiro esforço de revisar a literatura existente sobre a interação humana com ambientes naturais. Em 2008, Alves e Betrabet-Gulwadi fizeram outra revisão. Neste último trabalho são tratados 69 artigos publicados na revista Environment \& Behavior entre os anos de 1969 a 2002. Para essas autoras, ambientes naturais são definidos como "paisagens culturais" e, em graus variados, produtos da intervenção humana. Fundamentando-se em Rapoport (1992, apud ALVES \& BETRABET-GULWADI, 2008), afirmam que as paisagens culturais representam sistemas relacionados diretamente à ação humana por meio da atividade, onde a interação humana é afetada por preferências, esquemas, escolhas e limitações. 
Já o componente ambiente natural é formado pelas qualidades físicas (forma, textura, cor), qualidades espaciais (densidade), localidade (país, rural/ urbano, distante/próximo) e fatores organizacionais (regras formais e informais). Dessas surgem preferências, atração ou aversão, medo e outros benefícios relacionados à saúde.

Nas revisões acima citadas, o chamado Modelo de Kaplan (1995, 2001), sobre as preferências ambientais e a restauração da atenção, é bastante mencionado. É baseado na premissa de que o ambiente apresenta um conjunto de informações a serem processadas pelos indivíduos e que a exposição a ambientes naturais tem a capacidade de restaurar a atenção. $\mathrm{O}$ ambiente natural tem pois o potencial de "restaurar" níveis de atenção e assim reduzir níveis de stress. A teoria da restauração de níveis de atenção proposta por Kaplan credita ao ambiente natural propriedades informacionais denominadas de escape, mistério e compatibilidade que facilitariam tal processo. Essas propriedades não dizem respeito às características humanas ou ambientais per se, mas refletem a interação desses dois componentes. São considerados ambientes de restauração ou restauradores os que não exigem esforço da atenção e por isso permitem que a pessoa possa recuperar a capacidade de atenção perdida, circunstância acompanhada de sensações de bem-estar.

Os benefícios advindos da interação com ambientes naturais expande o entendimento à respeito das razões das pessoas preferirem ambientes naturais à ambientes urbanos. Ambientes construídos, como as cidades, são ricos em estímulos que exigem o direcionamento constante da atenção. Uma placa de trânsito, o semáforo que abriu, uma propaganda de roupas íntimas em um outdoor, a buzina de um carro ou o constante transitar de pessoas, são alguns exemplos corriqueiros. Para Kaplan (1995), essa sobrecarga de estímulos é uma das causas do adoecimento das pessoas. Mas existem outros elementos que influenciam nesse processo, tais como a relação que acaba se estabelecendo entre o ambiente (de onde provêm os estímulos) e o sujeito, que reage, na forma de ações comportamentais.

Kaplan (1995) desenvolveu um estudo que denominou de "os benefícios restauradores da natureza". Nesse trabalho reividenciou que determinados lugares possuem o poder de restabelecer o equilíbrio psíquico. Mas que lugares seriam esses? Tratam-se de lugares mobilizadores de uma atenção denominada de atenção involuntária, capaz de desonerar a sobrecarga de estímulos que levaram a atenção dirigida à exaustão. Imediatamente ao entrar nesses lugares, a pessoa é tomada por sua beleza, amplitude e relativa privacidade, o que possibilita um gradativo desaceleramento do processo cognitivo, fazendo os pensamentos moverem-se mais lentamente. Entretanto, a pessoa permanece consciente e, por meio da atenção informal, começa a perceber a natureza. As condições de saúde estariam relacionadas à desaceleração do processo cognitivo, 
Percepções da comunidade universitária sobre o Bosque do Planetário - Campus da UFSC

possibilitado pela atenção involuntária presente em ambientes restauradores e que promove o relaxamento do organismo. Assim sendo, uma maior compreensão dos mecanismos nos variados sistemas, capazes de mobilizar diferentes formas de atenção, pode ser significativa para o desenvolvimento de estratégias e técnicas capazes de promover a saúde.

\section{Contexto da pesquisa}

O campus universitário da UFSC na Trindade, onde se localiza a área em estudo, o Bosque do Planetário ou do $\mathrm{CFH}$, conta com aproximadamente 1 milhão de $\mathrm{m}^{2}$, inserido no bairro da Trindade, na região central da Ilha de Santa Catarina. A área do Bosque compreende vasta área verde cortada por um córrego, o planetário, a sede de um grupo de escoteiros e o Parque Viva a Ciência. Como fica ao lado do CFH (Centro de Filosofia e Ciências Humanas) é reconhecido como Bosque do CFH ou do Planetário, adminstrado pelo $\mathrm{CFH}$. A Figura 1 ilustra o local em foto aérea.

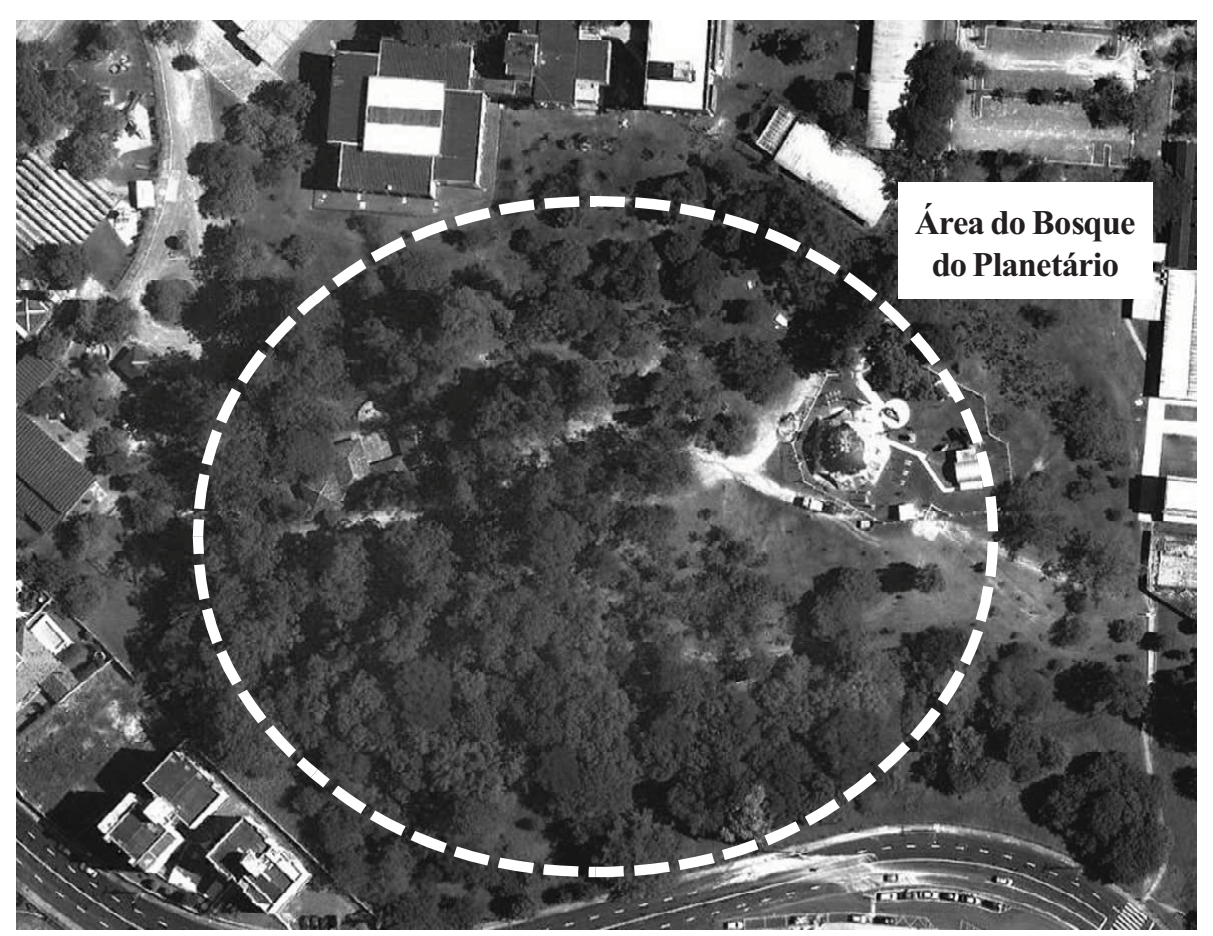

Figura 1

Vista áerea do Bosque do Planetário. 
Essa pesquisa buscou referendar conhecimentos na área de estudos pessoa-ambiente, aprofundando aportes acerca da importância de espaços ao ar livre e as repercussões da disponibilidade desses para a vida acadêmica universitária. Entende-se que muitas atividades que levam à fadiga mental são próprias do estilo de vida no campus, por isso seria importante se houvessem configurações espaciais restaurativas que permitissem manter-se o trabalho cognitivo. Para dar início a um conjunto de pesquisas sobre a temática, entendeu-se ser primordial começar por investigar a importância e os usos dados pela comunidade universitária ao Bosque do Planetário ou do $\mathrm{CFH}$ por se tratar de uma das maiores áreas livres no campus. Esse artigo apresenta os resultados desse enquete.

A continuidade da pesquisa sobre o assunto compreende mais dois projetos que estão em andamento. Um deles, está sendo desenvolvido durante o pós-doutoramento e outro projeto de pesquisa dará continuidade à pesquisa de campo na UFSC. Esse último compreende a aplicação de questionários específicos e escalas. De caráter exploratório, descritivo e correlacional utilizar-seão três escalas de medidas para acessar o fenômeno: WHOQOL-Bref, Perceived greenness e Perceived Restorativeness Scale. Nesses projetos compõem a base de referência fundamental o entendimento do que seja Qualidade de Vida pela OMS (Organização Mundial da Saúde - UNESCO), a Abordagem Bioecológica do Desenvolvimento Humano, a Teoria de Lugar e a Teoria da Restauração. Esse conjunto de projetos inserem-se num grupo de pesquisa de cooperação internacional (Estados Unidos, Escócia, Turquia e Brasil). Apresenta-se como contribuição a uma comparação intercultural de como os campi universitários são fontes de saúde durante a transição do ciclo vital dos estudantes e avaliação das áreas verdes dos campi assim como a contribuição dessas para a qualidade de vida e restauração.

\section{Método: participantes e local}

Os dados foram coletados nos 11 centros que compõe a UFSC: Centro de Ciências Agrárias (CCA), Centro de Ciências Biológicas (CCB), Centro de Comunicação e Expressão (CCE), Centro de Ciências Jurídicas (CCJ), Centro de Ciências da Saúde (CCS), Centro de Desportos (CDS), Centro de Ciências da Educação (CED), Centro de Filosofia e Ciências Humanas (CFH), Centro de Ciências Físicas e Matemáticas (CFM), Centro Sócio-Econômico (CSE), Centro Tecnológico (CTC). Participaram do estudo 1292 sujeitos. O projeto foi aprovado pelo Comitê de Ética com Seres Humanos da UFSC (processo 031/ $09 \mathrm{FR}-242841$, certificado ${ }^{\circ}$ 028). 


\section{Procedimentos e análise dos dados}

O instrumento foi um questionário aplicado através de entrevista com questões fechadas e abertas. A aplicação do questionário foi executada por pares de entrevistadores. Os dados foram coletados em lanchonetes e cafés, salas dos professores, corredores, coordenações e similares e, na fila do Restaurante Universitário no ano de 2009. Os dados foram tabulados e analisados com auxílio do programa estatístico Statistical Package for the Social Sciences (SPSS) versão 11. Foram feitas análises do tipo descritivo e relacional.

\section{Resultados e discussão}

Dentre os entrevistados, 1065 eram estudantes $(82,4 \%), 161$ professores $(12,5 \%)$ e 66 servidores $(5,1 \%)$. Esse número se refere a $5 \%$ dos alunos de cursos presenciais da UFSC e $10 \%$ dos professores e servidores, na ocasião da coleta de dados. Entre os respondentes 758 (58,7\%) eram do sexo masculino e $534(41,3 \%)$ do sexo feminino. A média de idade dos pesquisados foi de 26,08 anos.

Quase a totalidade $82,4 \%$ (1064 pessoas) disse já ter ouvido falar do Bosque, e 17,6\% (228 pessoas) disseram nunca ter ouvido falar a respeito. Quanto ao fato de terem ido ao local, 707 pessoas $(54,7 \%)$ disseram já ter ido alguma vez, e $585(45,3 \%)$ relataram nunca terem ido ao local. Em relação aos participantes que nunca foram ao Bosque (585 respondentes), os motivos apontados são: não sabia que existia (35\%); acho perigoso $(12,3 \%)$; falta de tempo $(11,4 \%)$; falta de oportunidade $(7,7 \%)$; não é caminho ( $6 \%)$; é longe (2,1\%); imagem negativa ( $1,2 \%)$; uso de drogas $(0,9 \%)$; não tem motivo $(23,2 \%)$.

Considerando a freqüência de ida ao Bosque por Centro, têm-se os seguintes dados: no $\mathrm{CCB}, \mathrm{CCE}, \mathrm{CDS}, \mathrm{CED}, \mathrm{CFH}$ e CFM o número de respondentes que foi ao Bosque é maior do que dos que nunca foram. Situação inversa ocorre no CCA, CCS, CSE e CTC, onde o número de respondentes que nunca foi ao Bosque supera o número de respondentes que já foi alguma vez. Quando perguntado sobre o interesse em conhecer o Bosque, 401 respondentes $(68,6 \%)$ disseram que gostariam de conhecer, e 184 respondentes $(31,4 \%)$ não demonstraram tal interesse. Em todos os Centros houve um maior número de interessados em conhecer o Bosque em relação aos não interessados, com exceção do CCE onde o número foi equivalente.

Os motivos mais evidenciados e que sustentam o uso do Bosque são: passagem (32,7\%); encontro com amigos (25,9\%); ida ao planetário (10,8\%); aula $(10,4 \%)$; uso de drogas $(6,4 \%)$; namoro (5\%); outros $(8,9 \%)$ (Figura 2$)$. 


\section{HUMANAS}

É importante destacar as duas escolhas de uso do Bosque mais evidenciadas pelos respondentes. Passar e encontrar os amigos representa mais da metade das atividades mencionadas, ou seja, 58,6\% dos entrevistados usam o Bosque para atividades que podem ser qualificadas como de lazer, descontração ou relaxamento.

Apesar da pesquisa não qualificar a escolha dos sujeitos por essas atividades, pode-se presumir que passar pelo Bosque indica uma opção por um caminho alternativo que reserva ao transeunte o contato com a natureza. Não havendo caminhos pré-estabelecidos ou calçadas, o passar pelo local é aleatório, o que reserva ao usuário a escolha de qual caminho seguir ao atravessar o Bosque para alcançar seu destino, seja o bairro vizinho, adentrar à UFSC ou simplesmente caminhar.

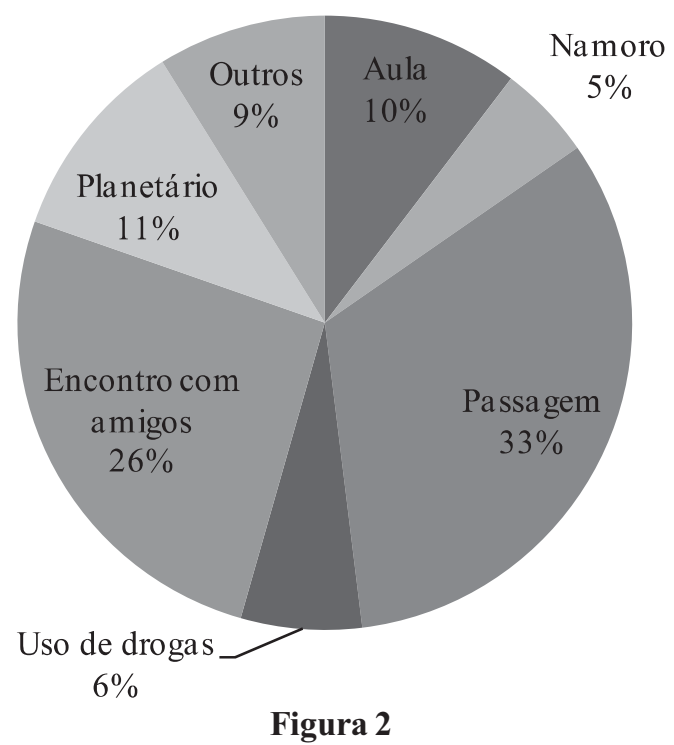

Finalidades de uso do Bosque do Planetário.

Tanto atravessar o local como encontrar os amigos evidenciam opções de uso do Bosque que indicam a valorização do local para atividades saudáveis em busca de bem-estar. Como indicado na literatura acima descrita, estudos vêm mostrando que o acesso aos espaços verdes e paisagens naturais afeta positivamente o humor, permite aprender e reter o conhecimento melhor, e ainda é responsável por produzir efeitos no corpo humano que os protegem facilitando as defesas imunológicas que nos tornam mais resistentes a doenças e alergias. Cada dia tem-se mais evidências da importância da conexão com a natureza como um componente vital de uma vida saudável, por exemplo, manter áreas verdes tem sido recomendado para combater os graves problemas de saúde de um estilo de vida cada vez mais sedentário, já que estimulam atividades físicas simples como caminhar. 


\section{Percepções da comunidade universitária sobre o Bosque do Planetário-Campus da UFSC}

Um importante aspecto a ser considerado para manter um espaço verde nas universidades ou escolas em geral é a eminência da fadiga mental, intrínseca à atividade intelectual. Os conhecidos sintomas da fadiga mental como desatenção, irritabilidade e controle dos impulsos podem ser aliviados no contato com a natureza. Atividades modestas em ambientes abertos (indicadas pelos entrevistados como caminhar ou encontrar amigos), com predominância de elementos naturais, podem aliviar a fadiga mental, especificamente, restaurando a capacidade de atenção dirigida, que é a capacidade de se concentrar e prestar atenção. Um tempo de descanso que renova a capacidade intelectual.

Outros dados destacáveis e merecedores de discussão aprofundada por indicar a mesma direção de outras pesquisas do gênero já apontadas acima, são os aspectos positivos apontados pelos entrevistados como o contato com a natureza (563 dos entrevistados), tranquilidade (404), silêncio (384), área de lazer (308) e, privacidade (127). ${ }^{2}$ Nesse aspecto melhor avaliam o uso do Bosque, os entrevistados do CCE, CFH e CTC. Os usuários provenientes desses Centros de Ensino destacam o valor do contato com a natureza.

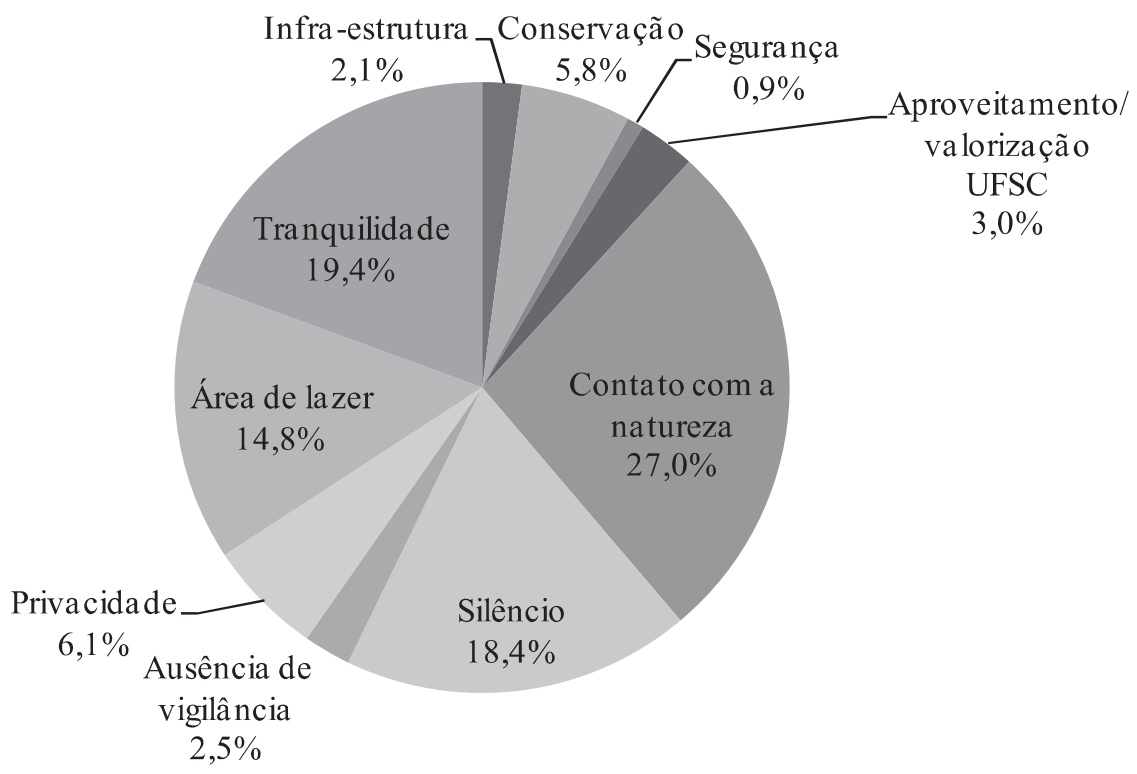

Figura 3

Aspectos positivos apontados em relação ao Bosque.

\footnotetext{
${ }^{2}$ Pelo fato do número de respostas de cada respondente variar entre 1 e 5 respostas os dados não são apresentados em forma de percentual, mas em número de respostas apontadas.
} 


\section{HUMANAS}

Salienta-se que os aspectos negativos demonstram serem rivais da possibilidade de contato com a natureza. Destacam-se também nesse conjunto os dados da Figura 4, onde surge a menção à falta de segurança (448), uso e o tráfico de drogas (342), ausência de vigilância (258), violência sexual (189), publicidade negativa (166), infra-estrutura (139), falta de divulgação (132), aproveitamento/valorização pela UFSC (127), falta de uso (121), conservação (110), presença de pessoas de fora da UFSC (86) e, silêncio (3).

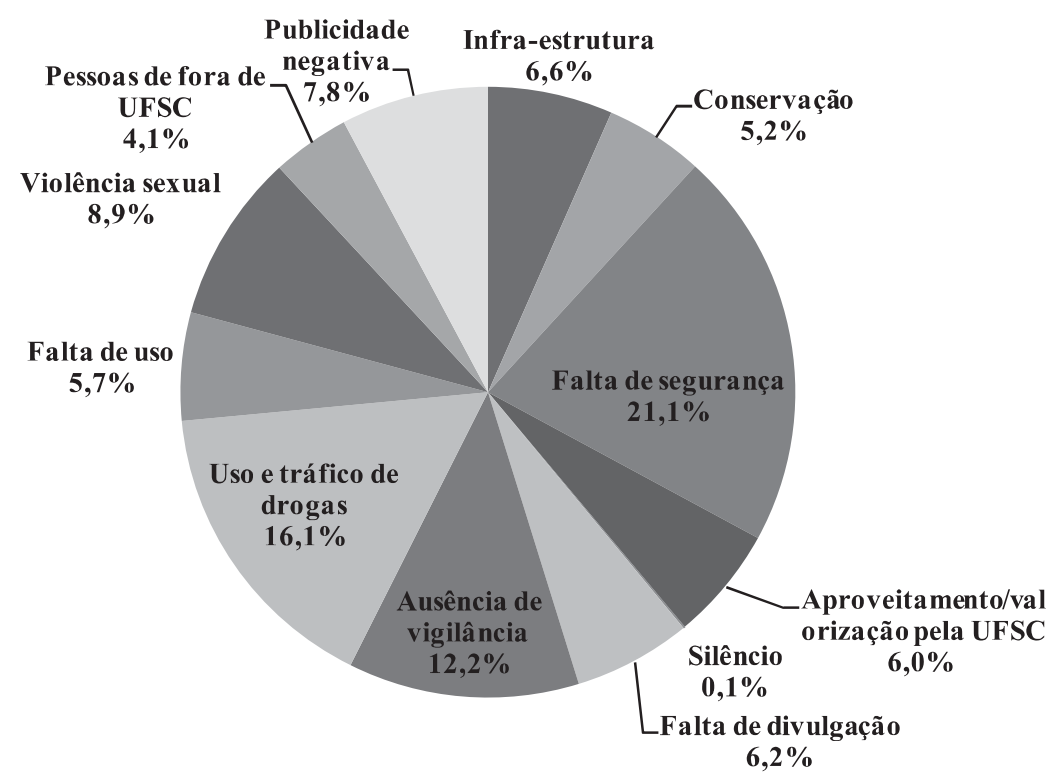

Figura 4

Aspectos negativos apontados em relação ao Bosque.

Ao se olhar os dados agrupando-se os itens relativos à segurança como falta de segurança, ausência de vigilância, violência sexual e uso e tráfico de drogas no local tem-se uma importante avaliação do local que aponta para as dificuldades ou impedimentos de uso adequado ou esperado de uma área verde dentro de um campus universitário. Parques e assemelhados, por serem áreas abertas, são comumente alvos de crimes, no entanto, quando bem planejados podem ajudar a proteger-se deles. A investigação acerca da relação entre vegetação urbana e crimes, comportamento agressivo e segurança não são conclusivas. Espaços descuidados oferecem uma imagem propícia ao crime.

$\mathrm{O}$ abandono ou a falta de infra-estrutura acaba por promover atividades que induzem ao uso inadequado de locais públicos. Por outro lado, a presença de incivilidades inibe a circulação de pessoas bem intencionadas, culminando numa circularidade de comportamentos inadequados: a presença de crimes e a 
ausência de uso adequado, uma dando espaço à outra sem se saber qual originou o que. A prevenção da criminalidade é um tema bastante complexo, mas já se sabe que lugares limpos, arejados, planejados para atividades saudáveis inibem a ocupação por delinqüentes.

Algumas visões se sobrepõem, mas de modo geral os criminologistas vêm mudando o foco do infrator e se concentrando mais no ambiente físico, como podendo influenciar o comportamento e em como as configurações espaciais podem permitir ou impedir atos criminosos.

A ocupação dos locais públicos parece que vem se concretizando como um novo movimento social mundial. Infelizmente os dados dessa pesquisa apontam contrariamente a essa direção. O Bosque tem sido evitado pela comunidade da UFSC. Em relação à freqüência de ida ao Bosque 84 respondentes $(11,9 \%)$ disseram ir sempre, $47(6,7 \%)$, freqüentemente, $90(12,7 \%)$ às vezes, $179(13,9 \%)$ raramente e, $306(43,3 \%)$ quase nunca. Os respondentes que não haviam ido uma única vez ao Bosque indicam não ter clareza de sua falta de motivação (194 pessoas alegam que não sabem o motivo), outros, apontam o uso de drogas no local (193), assalto (31) ou a violência sexual (29).

Recuperando um dado apresentado acima no texto, 707 pessoas entrevistadas ou $54,7 \%$ da amostra, disseram já ter ido alguma vez ao Bosque, enquanto 585 pessoas, $45,3 \%$ da amostra nunca foram ao local. Parece bastante significativo que a comunidade da UFSC divide-se quase que igualitariamente entre os que freqüentam e os que não freqüentam o Bosque. Vale ainda chamar a atenção que a pergunta indicava para pelo menos uma ida ao Bosque. Se pensarmos que qualitativamente tal freqüência não seja intensa, não é de estranhar que o local seja percebido como abandonado e inseguro, apesar das qualidades apontadas pelos que o freqüentam. Se recuperarmos outros dois dados importantes, de que $35 \%$ da amostra justifica não ir ao Bosque por não saber da sua existência e, $17,6 \%$ disseram nunca ter ouvido falar a respeito do local, podemos propor medidas de incentivo ao seu uso com base nos achados científicos que indicam a importância da natureza para a atividade acadêmica na universidade. Uma boa fonte de informação para uma intervenção nesse sentido são os dados por Centro de Ensino, que apontam, por exemplo, que nos seguintes centros: CCA, CCS, CSE e CTC o número de pessoas que nunca foi ao Bosque supera o número das que já foram alguma vez.

A menção a aspectos ambientais aprazíveis como o silêncio, a arborização, a amplitude, a sombra, o sol, a boa circulação de ar e a possibilidade de se sentar são destacadas na preferência por pátio escolar em recente estudo em uma importante instituição de ensino em Florianópolis (FELIPPE, 2010; FELIPPE \& KUHNEN, 2011; 2012). 


\section{HUMANAS}

Parece salutar ressaltar que a educação acontece além dos espaços formais como a sala de aula. A eficácia de um campus deve ser medida por sua capacidade de proporcionar e encorajar encontros entre a comunidade universitária. Desses provém trabalhos colaborativos, criativos, inovadores e engajados com osproblemas sociais. O Bosque, poderia ser um excelente espaço estimulante para esse projeto pedagógico. O que essa pesquisa demontra é que a presença de vegetação tem sido valorizada, apreciada e buscada. Um bom planejamento paisagítico e arquitetural poderia transformar o Bosque num parque científico, cultural e artístico de imenso valor para a comunidade universtária e para a cidade.

De um modo geral e no que tange a valorização da paisagem local tem-se uma avaliação positiva, por parte da comunidade universitária, acerca da qualidade do ambiente frente às suas necessidades. Parece bem evidente a partir dessa pesquisa que seria importante vincular uma avaliação dessa ordem à possibilidade de configurar-se em um sentimento de apego ao lugar. Ou seja, o referido ambiente possibilita o estabelecimento de certas funções e valores simbólicos e desencadeia vínculos emocionais com o lugar.

O apego ao lugar prova a existencia de apropriação do espaço, entendida como a atitude sobre o meio motivada pela sensação de pertencimento. É quando o sujeito, reconhecendo-se através do ambiente, permanece imprimindo sobre ele características particulares, que reforçam, por sua vez, a identidade de lugar. Tal reconhecimento torna-se importante para o bem-estar e para a preservação das qualidades do ambiente natural ou patrimonial e parece que tem-se esssa possibilidade dentro da comunidade da UFSC.

\section{Conclusões}

Um desafio essencial enfrentado no nível superior é a criação e a manutenção de ambientes que possam atrair, satisfazer e manter os estudantes em seus esforços para alcançar seus objetivos educacionais. Quando visualizamos a experiência dos tempos de faculdade imagens diferentes podem vir à nossa mente. Para alguns, tal experiência evoca imagens de passarelas cobertas de plantas, afastamento de atividades em ritmo acelerado da vida cotidiana. Para outros, traz à mente uma grande cidade com arranha-céus ou cafés perfeitos para reunião com professores e colegas. O que quer que as imagens destes pensamentos possam trazer é vital que os profissionais de planejamento do espaço físico reconheçam a importância que o ambiente do campus exerce.

O campus, apesar de ter alguns espaços ao ar livre, muitos edifícios são grandes e têm espaços interiores com pouca ou nenhuma exibição ao ar livre. 
Além disso esse espaço deve ser pensado como um importante contexto de desenvolvimento para os jovens estudantes. Segundo Owens $(2001 ;$ p.3) o espaço público é o principal lugar onde os jovens cumprem algumas das suas tarefas necessárias à sua transição para a idade adulta e pode, dependendo das suas características, "incentivar ou prejudicar o seu desenvolvimento social e emocional". O campus pode ser entendido como genius loci, não se resumindo apenas as qualidades distintivas físicas da universidade, mas também a sua integridade como uma comunidade e sua expressão arquitetônica e paisagística divulgando os ideais educacionais e sociais daquela instituição.

Esse conjunto de resultados coloca em evidencia uma provável relação entre a saúde e a adequação das características do ambiente às necessidades pessoais. Como identificam Evans e McCoy (1998), o "controle", definido como recurso de regulação e flexibilização do espaço, é uma das dimensões arquiteturais potencialmente capazes de afetar a saúde humana, estando associado, inclusive, ao desamparo aprendido. Restrições em ambientes incontroláveis poderiam estar relacionadas à produção e ao aumento de estresse. Embora se tenha noção dos limites desse estudo, os resultados aqui divulgados pretendem ajudar a entender e explicar os significados subjacentes que a comunidade da UFSC remete ao Bosque do Planetário. O papel dos gestores e as interações dos diversos setores e pessoas envolvidas nos processos de planejamento de novas construções no campus podem vir a se beneficiar desse conteúdo. Sabese contudo das complexas questões que envolvem o planejamento dos espaços.

Por último, esse artigo gostaria de chamar a atenção mais uma vez para as diversas influências dos espaços ao ar livre na saúde humana. No entanto, para compreender melhor as interações pessoa-ambiente e a dinâmica e os processos intervenientes várias fontes de informação sobre o contexto precisarão ser aprofundadas.

\section{Referências bibliográficas}

ALVES, S.M. \& BETRABET-GULWADI, G. Interação humana em ambientes naturais: uma revisão no periódico Environment \& Behavior. In: H. GUNTHER, H. \& J.Q. PINHEIRO (Orgs.). Métodos de pesquisa nos estudos pessoa-ambiente. p. 343-68. São Paulo: Casa do Psicólogo/All Books, 2008.

ARBOGAST, K.L.; KANE, B.C.P.; KIRWAN, J.L. \& HERTEL, B.R. Vegetation and outdoor recess time at elementary schools: What are the connections? Journal of Environmental Psychology, 29(4): 1-7, 2009.

BERG, A.E.; HARTIG, T. \& STAATS, H. Preference for nature in urbanized societies: Stress, restoration, and the pursuit of sustainability. Journal of Social Issues, 63(1): 79-96, 2007. 
EVANS, G. \& MCCOY, J. When buildings don't work: The role of architecture in human health. Journal of Environmental Psychology, 18:, 85-94, 1998.

FELIPPE, M.L. \& KUHNEN, A. Environmental care and place attachment: Perspectives for the sustainability issue in schools. Psyecology, 3(2): 205-16, 2012.

FELIPPE, M.L. \& KUHNEN, A. Vandalismo na escola: proposta de um modelo de avaliação do estado de conservação ambiental. Quaderns de Psicologia, 13(1): 63-79, 2011.

GEARIN, E.; KAHLE, C. Teen and adult perceptions of urban green space in Los Angeles. Children, youth and environments, 16(1): 25-48, 2006.

KAPLAN, S. The restorative benefits of nature: toward an integrative framework. Journal of Environmental Psychology, 15(3): 169-82, 1995.

KAPLAN, R. The nature of the view from home: Psychological benefits. Environment and Behavior, 33(4): 507-42. 2001.

KAPLAN, R.; KAPLAN, S. \& BROWN, T. Environmental preference: a comparison of four domains of predictors. Environment and Behavior, 21(5): 509-30, 1989.

MANZO, L.C. \& PERKINS, D. D. Finding common ground: the importance of place attachment to community participation and planning. Journal of Planning Literature, 20: 335-50, 2006.

MORRIS, N. Health, well-being and open space: literature review. OPENspace: the research centre for inclusive access to outdoor environments, Edinburgh College of Art and Heriot-Watt University, 2003 (http://www.openspace.eca.ac.uk, acesso em 25 de Fevereiro/2011).

OWENS, P.E. No teens allowed: the exclusion of adolescents from public spaces. Landscape Journal, 21(1): 156-63. 2001.

SHALLCROSS, T.; ROBINSON, J.; PACE, P. \& TAMOUTSELI, K. The role of students' voices and their influence on adults in creating more sustainable environments in three schools. Improving Schools, 10(1): 72-85, 2007.

TAYLOR, A.F. Coping with add the surprising connection to green play settings. Evironment and Behavior, 33(1): 54-77, 2001.

TAYLOR, A.F.; WILEY, A.; KUO, F.F. \& SULLIVAN, W.C. Growing up in the inner city... Environment and Behavior, 30: 3-27, 1998. 
TRAVLOU, P.; OWENS, P.E.; THOMPSON, C.W. \& MAXWELL, L. Environment, identity and experience: place-mapping as a method to understand teenagers' engagement with public places. Children's Geographies, 6(3): 309-26, 2008.

TENNESSEN, C.M. \& CIMPRICH, B. Views to nature: effects on attention. Journal of Environmental Psychology, 15: 77-85, 1995.

VELARDE, M.D.; FRY, G. \& TVEIT, M. Health effects of viewing landscapes: landscape types in environmental psychology. Urban Forestry \& Urban Greening, 6: 199-212, 2007.

WAKEFIELD, S.E.L.; ELLIOT, S.J.; COLE, D.C. \& EYLES, J.D. Environmental risk and (re)action: air quality, health, and civic involvement in an urban industrial neighbourhood. Health \& Place, 7: 163-77, 2001.

ZUBE, E.H.; SELL, J.L. \& TAYLOR, J.G. Landscape perception: research, application and theory. Landscape Planning, 9: 1-33. 1982. 